\title{
PILOT STUDY OF THE REMOVAL OF INDIVIDUAL TRIHALOMETHANES (thms) FROM CHLORINATED DRINKING WATER BY PAC ADSORPTION-GALATSI WATER TREATMENT PLANT, ATHENS, GREECE
}

\author{
BABI K.G.* \\ KOUMENIDES K.M. \\ NIKOLAOU A.D. \\ MAKRI C.A. \\ LEKKAS T.D.
}

Department of Environmental Studies

University of the Aegean

University Hill, 81100

Mytilene, Greece

Received: 02/06/12

Accepted: 20/09/12

*to whom all correspondence should be addressed: e-mail: kbabi@env.aegean.gr

\section{ABSTRACT}

The objective of this pilot study was to evaluate the performance of Powdered Activated Carbon (PAC) for the removal of individual trihalomethanes (THMs) from chlorinated drinking water, Athens, Greece.

The pilot treatment facility was located at the Water Treatment Plant of EYDAP (Athens Water Supply and Sewerage Company) in Galatsi, Athens, and consisted of two mixing tanks operating as open batch reactors, which were fed with chlorinated water from the overflow of the sedimentation tanks. Experimental cycles were performed, with different PAC doses ranging from 5 to $50 \mathrm{mg} \mathrm{L}^{-1}$ and with contact times 30 and 60 min for each cycle. Water samples taken at the start of each cycle and after contact with PAC, were analysed for individual THMs and Dissolved Organic Carbon (DOC). Bromide, free residual chlorine, $\mathrm{pH}$ and temperature were also measured.

From the experimental results, it was shown that all THMs concentrations were decreased after PAC contact, the decrease being higher for higher PAC dose and higher contact time, with few exceptions. This fact probably indicates that adsorption rate plus volatilisation rate of THMs overcame formation rate, in most cases.

It was also concluded that volatilisation and possible formation reactions of THMs had probably a more apparent effect to the total removal of most THMs at low PAC doses and low contact time. At higher PAC doses and higher contact time, PAC adsorption probably had an increased contribution to THMs removal, because of the larger carbon surface area and the longer contact time, resulting in higher adsorbed mass according to adsorption theory.

By using isotherm results of individual THMs on activated carbon by other researchers, the theoretically adsorbed mass of THMs per $g$ of PAC was roughly estimated and compared with the measured removed mass of THMs per $\mathrm{g}$ of PAC at PAC dose $50 \mathrm{mg} \mathrm{L}^{-1}$ and contact time 60 min for most THMs, on the assumption of equilibrium achievement. The removed mass of THMs by PAC appeared much higher than the theoretically adsorbed, especially for the most volatile members. The difference was attributed to volatilisation taking place in the open mixing tanks.

In conclusion, the practical results from the application of PAC for the removal of THMs are much better than expected from single adsorption by PAC. Volatility of THMs, especially of chloroform (TCM), substitutes for weak adsorbability and gives increased removal.

The influent DOC was almost constant in all experiments. The removal of DOC was generally higher for increased PAC dose and contact time. The mass removal of DOC per $\mathrm{g}$ of PAC was higher by more than two orders of size than that of the smaller and in lower concentration THMs, as was expected.

KEYWORDS: THMs, TCM, BDCM, DBCM, TBM, DOC, PAC, adsorption, drinking water treatment. 


\section{INTRODUCTION}

Chlorination is the most common disinfection method of drinking water. Although it is important to the supply of safe drinking water, it also leads to the formation of undesirable organic-by-products (Disinfection-by-products, DBPs). A main class of chlorination- by-products is trihalomethanes $(\mathrm{THMs})^{1}$ (Arora et al., 1997). They are formed when chlorine reacts with bromide $\left(\mathrm{Br}^{-}\right)$and natural organic matter (NOM) in source waters (Nikolaou et al., 2004; Chowdhury et al., 2008).

Toxicology studies have shown all THMs, among other DBPs, to be carcinogenic or to cause adverse reproductive or developmental effects in laboratory animals (AWWA, 1990; USEPA, 2001; WHO, 2004; Nieuwenhuijsen, 2005). Because of this serious health risk, regulatory action has been taken to control the levels of these DBPs in finished drinking water. Maximum allowable levels for THMs have been set as follows: for TTHMs $100 \mu \mathrm{g} \mathrm{L}-1$ by EEC (1998) and $80 \mu \mathrm{g} \mathrm{L}-1$ by US Environmental Protection Agency (USEPA, 1998), while for individual THMs: TCM, BDCM, DBCM and TMB: 200, 60, 100 and $100 \mu \mathrm{L} \mathrm{L}-1$ respectively by World Health Organization (WHO, 2004).

Among other alternatives for the control of THMs and DBP precursors in drinking water, activated carbon, either in granular form (GAC) or powdered form (PAC), has been of a special interest due to its ability to remove a wide range of compounds such as odor and color causing compounds, NOM, THMs and other toxic compounds (Speth and Miltner, 1990; Clark et al., 1991; Babi et al., 2003; 2007). GAC and PAC have already been used in many water treatment plants in Europe and in the U.S.A. (AWWA, 1990; Sandrucci et al., 1995).

\section{BACKGROUND}

All four THMs are volatile compounds and weakly adsorbable on activated carbon. They can be removed from water by air stripping and adsorption by activated carbon (AWWA, 1990; Babi et al., 2003; 2007; Singer et al., 1994; Dvorak et al., 1993).

According to isotherm results by other researchers, activated carbon has the lowest capacity for chloroform as compared with the other THM compounds. The higher the number of bromine atoms in THM molecules, the better they are adsorbed to activated carbon (Speth and Miltner, 1990; AWWA, 1990).

However, adsorption isotherms do not generally give accurate predictions for real situations (Speth and Miltner, 1990). On-site pilot studies can give a better approximation of full-scale performance of activated carbon, either granular of powdered (AWWA, 1990; Sandrucci et al., 1995; USEPA, 2001).

Powdered activated carbon (PAC) is commonly used to remove seasonal taste and odor problems from surface water. PAC can also remove synthetic organic chemicals (SOCs), herbicides, color, THMs and other DBPs, as well as their precursors (AWWA, 1990).

The primary characteristic of PAC that differentiates it from GAC is its particle size. Typically, 65-95 percent of commercially available PAC passes through a 325-mesh $(44 \mu \mathrm{m})$ sieve. The particle size distribution is important because the smaller PAC particles adsorb organic compounds more rapidly than larger particles (Najm et al., 1990).

PAC has the advantages of being a cheaper material than GAC and of requiring little capital expediture for feeding and contacting equipment. Also, it can be applied only when needed. However, PAC cannot be regenerated and has higher carbon usage rates.

Important criteria for selecting the point of addition of PAC, which affects PAC performance, include (1) the provision of good mixing (2) sufficient time of contact (3) minimal interference by treatment chemicals with adsorption on PAC, and (4) no degradation of finished water quality (Najm et al., 1990; 1991).

In a conventional treatment plant, among other alternatives a separate PAC reactor between the sedimentation tank and the filter has the advantage of longer contact time and elimination of competing organics by sedimentation (Najm et al., 1991).

The time required for contact is an important function of the characteristics and concentration of the molecule to be adsorbed. As the molecular size increases, the rate of diffusion decreases and more

1 THMs: chloroform (TCM), bromodichloromethane (BDCM), dibromochloromethane (DBCM), bromoform (TBM). The sum of THMs in this work: TTHMs. 
time is required for contact. If contact time is insufficient for equilibration, an increased PAC dose must be added to compensate (Najm et al., 1991).

The actual dose of PAC required for a certainTHM removal is dependent on the type of PAC used, the presence of other competing organics in water and the time allowed for adsorption or the degree of mixing being sufficient for equilibrium to be reached.

The reported removals of THMs and THM precursors from drinking water by PAC range from poor to very good (AWWA, 1990).

Previous research has showed the occurrence of THMs and natural organic matter in the chlorinated finished drinking water of Athens (Golfinopoulos et al., 2005). The removal of the above groups of compounds by GAC has been studied on a pilot-scale (Lekkas et al., 2008; Babi et al., 2008; 2009).

The objective of this pilot study is to evaluate the performance of PAC for the removal of individual THMs from prechlorinated water after sedimentation under real conditions, with PAC added in a separate tank between the sedimentation tank and the sand filter.

\section{MATERIALS AND METHODS}

\subsection{Powdered Activated Carbon}

Norit Sam 52 was selected for our experiments because it is considered to be especially suitable for the removal of dissolved organic matter from drinking water. Its general characteristics, according to the manufacturer, are: Apparent density (tamped): $450 \mathrm{~kg} \mathrm{~m}^{-3}$, Particle size D50: $20 \mu \mathrm{m}$, lodine number: 650, Methylene Blue adsorption: $12 \mathrm{~g} / 100 \mathrm{~g}$, Total surface area (BET): $725 \mathrm{~m}^{2} \mathrm{~g} \mathrm{~g}^{-1}$, Ash content: 6 mass-\%, pH: alkaline. The PAC doses applied in our experiments ranged from 5 to $50 \mathrm{mg}$ $\mathrm{L}^{-1}$ and were chosen according to literature (AWWA, 1990; Sandrucci et al., 1995; Najm et al., 1991).

\subsection{Pilot-plant operation}

The pilot- plant experiments were conducted in Galatsi Water Treatment Plant (GWTP), which receives surface water from Mornos and Marathon water bodies. Conventional treatment is applied in the plant including prechlorination, coagulation, flocculation, sedimentation, rapid gravity sand filtration and postchlorination.

The pilot treatment facility consists of two cylindrical mixing tanks of $650 \mathrm{~L}$, constructed of polypropylene and equipped each with a mixer $0.250 \mathrm{kw}$, helix type. The tanks were fed with prechlorinated water coming from the overflow of the sedimentation tanks by gravity through a polypropylene tube.

The mixing tanks were operated as batch reactors. Each experimental cycle included the steps: (1) filling of the tank with $500 \mathrm{~L}$ of feed water (2) addition of the chosen PAC dose under mixing (3) mixing of water for $30 \mathrm{~min}$ or $60 \mathrm{~min}$, and (4) stop of mixing, evacuation and washing of the tank. Six experimental cycles were performed with six different PAC doses $\left(5,10,20,30,40\right.$ and $\left.50 \mathrm{mg} \mathrm{L}^{-1}\right)$ and two different contact times (30 min and $60 \mathrm{~min}$ ) for each PAC dose.

During each experimental cycle, 3 sampling events took place: at the start and after mixing and contact with PAC for 30 min and 60 min, respectively.

\subsection{Sample preparation and analysis}

The samples were filtered through $0.45 \mu \mathrm{m}$ polypropylene filter and analysed for individual THMs and DOC. Also, $\mathrm{pH}$, temperature, free residual chlorine and bromide ion were measured. Sample preparation and preservation were performed according to Standard Methods (APHA, 1992).

Methods used for analyses were: THMs: LLE (with MTBE)-GC-ECD: USEPA method 551.1 (USEPA, 1998a; Nikolaou et al., 2002a); DOC: Combustion- infrared method after sample filtration through $0.45 \mu \mathrm{m}$ syringe filter; Free chlorine: DPD colorimetric method; Bromide: Ion Chromatography; Temperature, $\mathrm{pH}$ : Standard Methods (APHA, 1992).

THMs analyses were performed in the Water and Air Quality Laboratory of the Department of Environmental Studies of the University of the Aegean, while DOC analyses were performed in Polydendri Laboratory of EYDAP and the rest of the analyses and measurements in Galatsi Laboratory of EYDAP. 


\section{RESULTS AND DISCUSSION}

\subsection{Experimental results}

Some physicochemical parameters, like temperature and $\mathrm{pH}$, did not change significantly after PAC contact. A small increase in $\mathrm{pH}$ was attributed to the alkalinity of PAC.

Free residual chlorine $\left(0.34 \mathrm{mg} \mathrm{L}^{-1}\right)$ was reduced after contact with PAC to 0.18 and $0.16 \mathrm{mg} \mathrm{L}^{-1}$ after 30 and 60 min contact, respectively. Bromide was low $\left(10 \mu \mathrm{g} \mathrm{L}^{-1}\right)$ and was reduced after PAC contact (7 and $6 \mu \mathrm{g} \mathrm{L}-1$ after 30 and $60 \mathrm{~min}$, respectively).

Free residual chlorine reduction was partly caused by the catalytic action of PAC (AWWA, 1990) and partly by volatilisation and/or incorporation in DOC by formation reactions of DBPs. The latter is supported by the reduction of bromide, which can not be attributed to PAC (AWWA, 1990).

\subsection{Individual THMs and DOC results and calculations}

\subsubsection{Removal of THMs}

THMs are small volatile molecules, which are hydrophobic and non biodegradable. Chloroform (TCM) is smaller molecule, more volatile and more water soluble than the brominated members. THMs are adsorbed on activated carbon to some extent (AWWA, 1990; Speth and Miltner, 1990; Dvorak et al., 1993; Arora et al., 1997).

The change of THMs concentration in water after PAC addition and continuous mixing for 30 or 60 min can be attributed to (a) net adsorption of THMs on PAC (adsorption minus desorption) (b) volatilisation of THMs due to continuous mixing (aeration) of water, and (c) formation of new THMs molecules, through possibly continuing formation reactions of organic matter with free chlorine and bromide in water.

We can assume that removal of THMs is the net result of adsorption plus volatilisation minus formation of THMs.

From Figures 1-4 the following are observed about individual THMs removal after PAC addition:

TCM and BDCM average influent concentrations were $39.57 \mu \mathrm{g} \mathrm{L}^{-1}$ and $66.53 \mu \mathrm{g} \mathrm{L}^{-1}$. Both, TCM and BDCM concentrations were generally decreased after PAC contact, the decrease being higher for higher PAC dose and contact time (Figures 1,2). This result probably indicates that generally adsorption rate plus volatilisation rate of both TCM and BDCM overcame formation rate.

Few exceptions were observed: TCM concentration at PAC doses 5 and $30 \mathrm{mg} \mathrm{L}^{-1}$ and for $30 \mathrm{~min}$ contact time was found higher than influent, indicating that probably the TCM formation reaction rate overcame adsorption and volatilisation rates at low PAC doses and contact time. On the other hand, BDCM influent concentration remained the same after PAC contact for $30 \mathrm{~min}$ and at PAC doses 10 and $30 \mathrm{mg} \mathrm{L}^{-1}$, fact which shows that probably BDCM formation rate was equal to the sum of adsorption and volatilisation rates. Another exception, is that at PAC doses 20 and $40 \mathrm{mg} \mathrm{L}^{-1}$, TCM and BDCM removals for 60 min contact were lower than or equal to those for 30 min contact, fact which could be explained by either higher formation during the 60 min contact and/or desorption of the above species due to competition by other organics or newly formed DBPs (Thacker et al., 1983; AWWA, 1990).

It was also observed that at PAC doses higher than $20 \mathrm{mg} \mathrm{L}^{-1}$ and contact time $60 \mathrm{~min}$, the removal of TCM and BDCM was almost constantly higher for higher PAC dose.

$D B C M$ and TBM average influent concentrations were $102.30 \mu \mathrm{g} \mathrm{L}^{-1}$ and $2.40 \mu \mathrm{g} \mathrm{L}^{-1}$. Both, DBCM and TBM concentrations were generally decreased after PAC contact, the decrease being higher for higher PAC dose and higher contact time (Figures 3, 4), as was also observed for TCM and BDCM.

Exceptionally, at PAC doses 20 and $40 \mathrm{mg} \mathrm{L}^{-1}$, DBCM removal for 30 min contact time was almost as high as that for $60 \mathrm{~min}$ contact time. This is probably due to higher formation during the $60 \mathrm{~min}$ contact and/or desorption of the above species due to competition by other organics or newly formed DBPs (Thacker et al., 1983; AWWA, 1990), as was mentioned about TCM and BDCM.

It was also observed that for contact time $60 \mathrm{~min}$ and all PAC doses, the removal of DBCM and TBM was almost constantly higher for higher PAC dose. At PAC doses 40 and $50 \mathrm{mg} \mathrm{L}^{-1}$ and for both contact times TBM in effluent water was lower than the detection limit $\left(0.01 \mu \mathrm{g} \mathrm{L}^{-1}\right)$. 


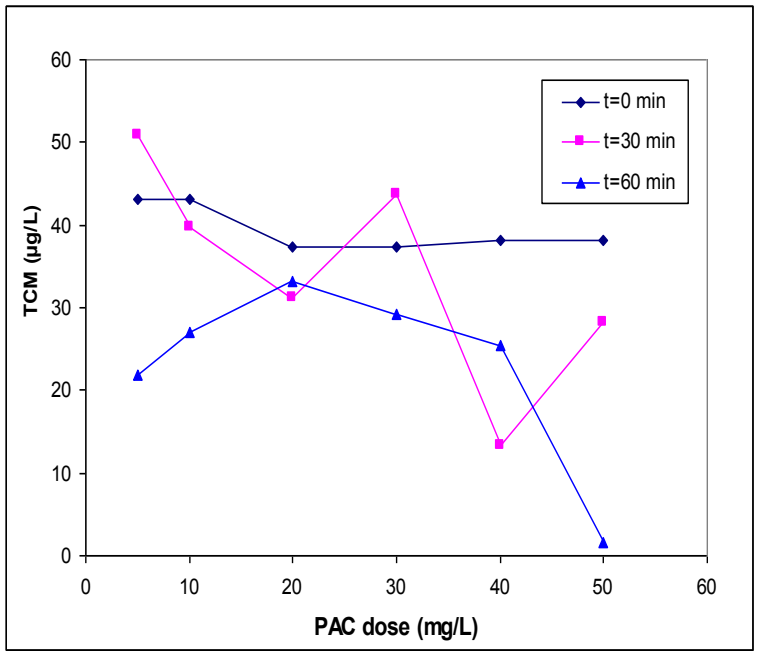

Figure 1. TCM in influent and effluent for different PAC doses and contact times

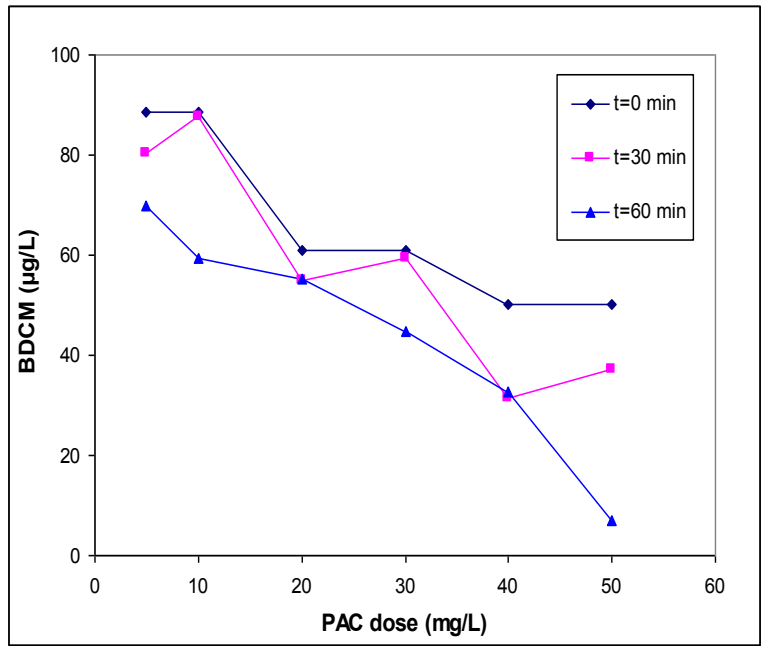

Figure 2. BDCM in influent and effluent for differe PAC doses and contact times
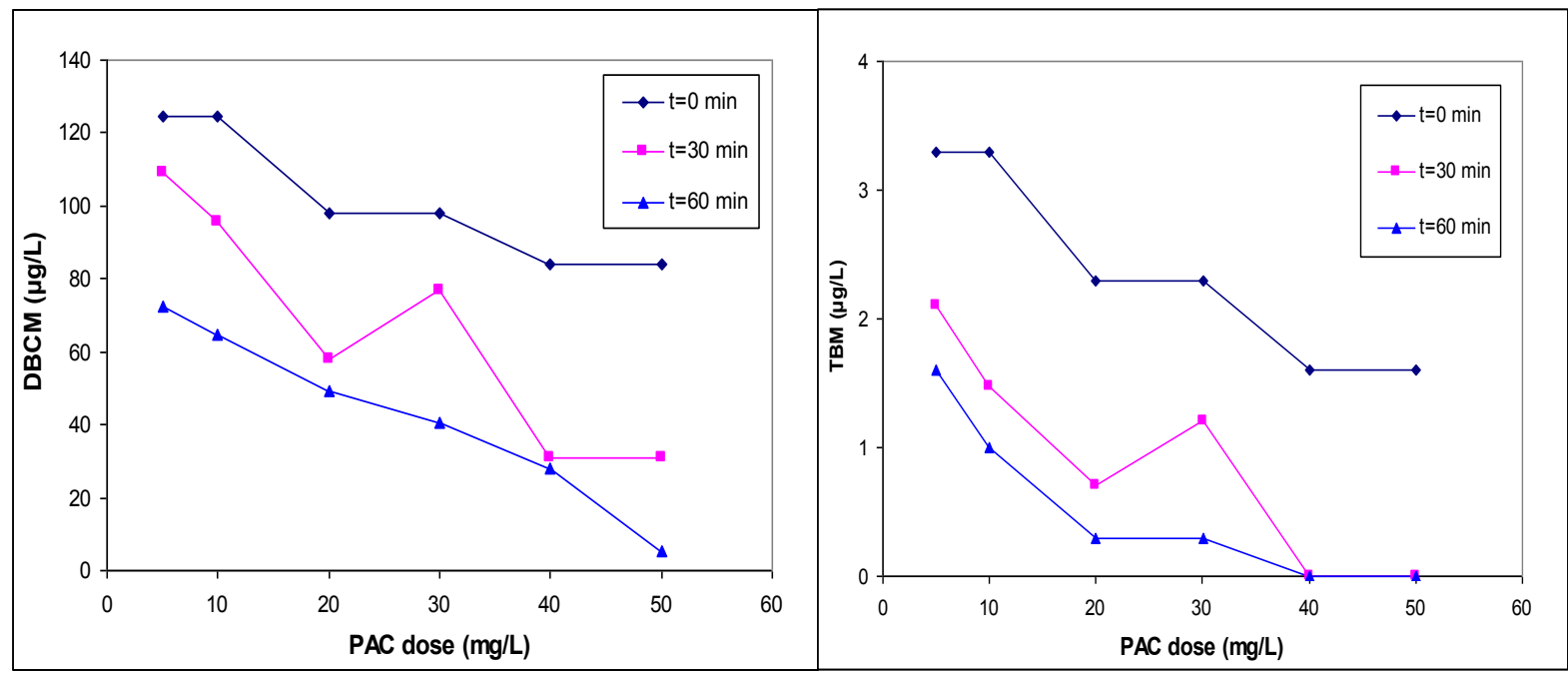

Figure 3. DBCM in influent and effluent for differe Figure 4. TBM in influent and effluent for different PAC doses and contact times PAC doses and contact times

Higher influent concentration of THMs was observed in the experiments with low PAC doses. This results in higher adsorption rate (AWWA, 1990) and higher removed mass by volatilisation, according to Henry's law (Treybal, 1980). It was also concluded that possible THMs formation reactions had a more apparent effect to the removal of most THMs at low PAC doses and low contact time. At higher PAC doses and higher contact time, PAC adsorption probably had an increased contribution to THMs removal, because of the larger carbon surface area and the longer contact time, resulting in higher adsorbed mass according to adsorption theory (AWWA, 1990; Treybal, 1980).

\section{Comparison of experimental results with isotherm results by other researchers}

The following method of rough estimation of the removal of individual THMs by adsorption on PAC and by volatilisation could help us assess the practical results from the application of PAC.

For this purpose, we could roughly compare our experimental results concerning THMs removal by PAC with the isotherm results for THMs on activated carbon by other researchers, under certain assumptions. 
The Freundlich adsorption isotherm constants $\mathrm{K}$ and $1 / \mathrm{n}$ for individual THMs in distilled-deionized water on granular activated carbon (Filtrasorb 400, Calgon corp.) have been determined by Speth and Miltner (1990) and are presented in Table 1.

Table 1. Isotherm results*

\begin{tabular}{llll}
\hline Adsorbate & $\mathbf{C}_{\mathrm{e}}$ range & Freundlich constants & \\
\hline Individual THMs & $\left(\mu \mathrm{L} \mathrm{L}^{-1}\right)$ & $\begin{array}{l}\boldsymbol{K} \\
\left(\mu g g^{-1}\right)\left(\mathrm{L}^{-1}\right)^{1 / n}\end{array}$ & $\mathbf{1 / n}$ \\
\hline TCM & $226.0-13.2$ & 92.5 & 0.669 \\
\hline BDCM & $333.0-12.0$ & 241.0 & 0.655 \\
\hline DBCM & $116.0-5.0$ & 585.0 & 0.636 \\
\hline TBM & $130.0-1.9$ & 929.0 & 0.665 \\
\hline
\end{tabular}

${ }^{*}$ activated carbon: F-400, Calgon corp. (Speth and Miltner, 1990)

Since $1 / n$ values, which are related to the strength of adsorption, are similar for all THMs, the larger the $\mathrm{K}$ value, the larger the carbon capacity qe for a specific THM species, for fixed values of $\mathrm{Ce}$ (equilibrium concentration). From comparison of $\mathrm{K}$ values, it is obvious that the more brominated THMs are better adsorbed by activated carbon (Table 1). This result has been confirmed by other researchers (AWWA, 1990; Clark et al., 1991).

Natural water isotherms show generally a different, usually lower, carbon capacity compared with distilled-deionized water isotherms, because of different background matrixes of the natural water, with different adsorbabilities of compounds and competitive adsorption. However, in case of TCM and TBM, carbon capacity was found higher for natural water (Speth and Miltner, 1990).

It has also been shown that the isotherm of the single compound will be a function of the initial concentration of background organics and the carbon dose if competition orccurs between them (Randtke and Snoeyink, 1983).

The adsorption capacity of a carbon sample is not altered by crushing it to a smaller particle size. As molecular size of adsorbate and carbon particle size increase, the rate of adsorption decreases (Randtke and Snoeyink, 1983). Experimental data by other researchers have shown that for small molecules and carbon particle size $44 \mu \mathrm{m}, 15$ minutes contact are enough for equilibration, while for large molecules some days may be needed (AWWA, 1990).

According to the above conclusions, we can assume that 60 min contact time was enough for equilibration between the low- molecular- weight four THMs and the PAC particles (D50: $20 \mu \mathrm{m}$ ), in our experiments.

If we consider that equilibrium was achieved for TCM, BDCM and DBCM at PAC dose $50 \mathrm{mg} \mathrm{L}^{-1}$ and contact time $60 \mathrm{~min}$ and for TBM at PAC dose $40 \mathrm{mg} \mathrm{L}^{-1}$ and contact time $60 \mathrm{~min}$ (as seen in Figure 4), the equilibrium concentrations $\mathrm{Ce}$ of THMs are the effluent THMs concentrations. If we assume that the $\mathrm{K}$ and $1 / \mathrm{n}$ values for THMs given by Speth and Miltner (Table 1) for distilled-deionized water are almost the same for our chlorinated water after sedimentation, we can use the Freundlich equation (1) and calculate the equilibrium surface concentrations qe for the same Ce and carbon type F-400 ( $q$ adsorbed by F-400, theoretical), presented in Table 2.

$\mathrm{qe}=\mathrm{KCe}^{1 / \mathrm{n}}$

However, F-400 is characterised by BET surface area $1100 \mathrm{~m}^{2} \mathrm{~g}^{-1}$ and minimum iodine number 1050, while PAC used in our experiments has a BET surface area $725 \mathrm{~m}^{2} \mathrm{~g}^{-1}$ and iodine number 650. Consequently, the equilibrium PAC concentration $\left(q_{A}, q\right.$ adsorbed by $P A C$, theoretical) of each of THMs is expected to be lower than that of F-400 (qe, q adsorbed by F-400, theoretical).

Since iodine number represents carbon adsorption capacity for small molecules such as THMs, we could arbitrarily assume that the equilibrium concentrations of F-400 and PAC for each of THMs are proportional to the activated carbons' iodine numbers. So, the theoretical q adsorbed by PAC $\left(q_{A}\right)$ can be considered approximately equal to that of F-400 multiplied by the factor $650 / 1050=0.62$, that is:

$q_{A}=q e \times 0.62$

The $q_{A}$ values are also presented in Table 2. 
The use of natural water instead of one-solute solution is considered to make no significant difference to the above theoretical results about PAC. Consequently, the effect of competitive adsorption and THMs formation reactions is also considered negligible for this PAC dose and contact time.

The practically removed mass of each THMs per $g$ of PAC ( $q$ removed by PAC, $q_{R}$ ) for 60 min contact time and PAC dose $50 \mathrm{mg} \mathrm{L}^{-1}$ for all THMs except TBM (PAC dose $40 \mathrm{mg} \mathrm{L}^{-1}$ ) is calculated from the mass balance of individual THMs (equation 3 ) on the reactor and the results are also presented in Table 2.

$\mathrm{q}_{\mathrm{R}}=(\mathrm{Co}-\mathrm{Ce}) / \mathrm{PAC}$ dose

where $q_{R}$ is the concentration removed by PAC, Co is the influent concentration and $C e$ is the equilibrium (effluent) concentration.

Table 2. Estimated removed mass of individual THMs per $\mathrm{g}$ of PAC by adsorption and by volatilisation at PAC dose $50 \mathrm{mg} \mathrm{L}^{-1}$ and contact time $60 \mathrm{~min}$

\begin{tabular}{llllllll}
\hline THMs & $\begin{array}{l}\text { Co } \\
\text { influent }\end{array}$ & $\begin{array}{l}\text { Ce } \\
\text { effluent }\end{array}$ & $\begin{array}{l}\mathbf{q e} \\
\text { adsorbed } \\
\text { by F-400 } \\
\text { (theoretical) }\end{array}$ & $\begin{array}{l}\mathbf{q}_{A} \\
\text { adsorbed } \\
\text { by PAC } \\
\text { (theoretical) }\end{array}$ & $\begin{array}{l}\mathbf{q}_{\mathbf{R}} \\
\text { removed } \\
\text { by PAC }\end{array}$ & $\begin{array}{l}\mathbf{q}_{R^{-}} \mathbf{q}_{\mathbf{A}} \\
\text { volatilisation } \\
\left(\mathbf{q}_{\mathbf{v}}\right)\end{array}$ & $\mathbf{q}_{\mathrm{R}} / \mathbf{q}_{\mathbf{v}}$ \\
\cline { 2 - 8 } & $\mu \mathrm{g} \mathrm{L}^{-1}$ & $\mu \mathrm{g} \mathrm{L}^{-1}$ & $\mu \mathrm{g} \mathrm{g}^{-1} \mathrm{~F}-400$ & $\mu \mathrm{g} \mathrm{g}^{-1} \mathrm{PAC}$ & $\mu \mathrm{g} \mathrm{g}^{-1} \mathrm{PAC}$ & $\mu \mathrm{g} \mathrm{g}^{-1} \mathrm{PAC}$ & \\
\hline TCM & 38.20 & 1.50 & 121.32 & 75.22 & 734.00 & 658.78 & 9.76 \\
\hline BDCM & 50.10 & 7.10 & 870.14 & 539.49 & 860.00 & 320.51 & 1.59 \\
\hline DBCM & 84.10 & 5.20 & 1669.30 & 1034.97 & 1578.00 & 543.03 & 1.52 \\
\hline TBM $^{*}$ & 1.60 & 0.01 & 40.51 & 25.12 & 39.78 & 14.66 & 1.58 \\
\hline
\end{tabular}

${ }^{*}$ For TBM: $\mathrm{Ce}=0.009 \mu \mathrm{g} \mathrm{L}-1$ approx. (lower than detection limit 0.01), PAC dose: $40 \mathrm{mg} \mathrm{L}^{-1}$.

From the comparison of $q$ removed by PAC $\left(q_{R}\right)$ and $q$ adsorbed by PAC $\left(q_{A}\right)$ for individual THMs, we see that the real removal of THMs was considerably higher than the theoretically expected due to adsorption (Table 2). The difference qv between them can be attributed to volatilisation, which takes place in the open mixing tanks in our experiments, but is not allowed to take place during isotherm experiments for volatile compounds (AWWA, 1990).

The above rough comparison showed that the mass removal of TCM per $\mathrm{g}$ of PAC was 9.76 times higher than expected by single adsorption by PAC, the one of BDCM 1.59 times higher, the one of DBCM 1.52 times higher and that of TBM 1.58 times higher (Table 2).

From the above, it was shown that the removal capacity of PAC for THMs is higher than its adsorption capacity for them, because it is highly enhanced by volatilisation, especially for the most volatile members. However, even if the adsorption capacity of PAC were equal to that of F-400, which is not the case, the removal of the most volatile chloroform would still be 6 times higher than the expected from single adsorption, as comparison of $\mathrm{q}_{\mathrm{R}}$ and qe shows (Table 2).

In conclusion, the practical results from the application of PAC are much better than expected from single adsorption as to the removal of THMs. Volatility of THMs, especially of chloroform, substitutes for weak adsorbability and gives increased removal.

\subsubsection{Removal of DOC}

The change of DOC in water after PAC addition could be attributed to (a) net adsorption of DOC by PAC (adsorption minus desorption) (b) incorporation of free chlorine and bromide into dissolved organic matter through formation reactions of new DBPs and (c) removal of volatile organics due to continuous mixing (aeration) of water.

The DOC increase due to chlorine and bromine incorporation by DBPs formation reactions might be at a maximum level equal to the average free chlorine removal, that is about $0.15 \mathrm{mg} \mathrm{L}^{-1}$, which is lower than mean influent DOC (1.61 $\left.\mathrm{mg} \mathrm{L}^{-1}\right)$ and could be considered negligible (AWWA, 1990). In addition, the volatile organics content of DOC is low, because most part of them has been removed in preceding stages of treatment. Furthermore, biodegradation of DOC cannot have taken place, because of the presence of free chlorine in water and the residence time being too short to allow the development of a chlorine resistant microbial population (AWWA, 1990). In conclusion, adsorption can be considered the main removal mechanism for DOC in water after contact with PAC. 
The influent concentration of DOC was almost constant in all experiments, ranging from 1.59-1.62 $\mathrm{mg} \mathrm{L}^{-1}$. The \% removal of DOC for both contact times was generally higher for increased PAC dose and contact time, with few exceptions. At PAC dose $50 \mathrm{mg} \mathrm{L}^{-1}$ and 60 min contact time, the observed $\%$ removal of DOC was $32.08 \%$, while the mass removal of DOC was $10.20 \mathrm{mg} \mathrm{DOC}$ per $\mathrm{g}$ of PAC. The contact time of 60 min was possibly too short to allow equilibration of DOC, as has been proven by other researchers (Randtke and Snoeyink, 1983). The mass removal of DOC was higher by more than two orders of size than that of the smaller and in lower concentration THMs, as was expected.

\section{CONCLUSIONS}

From the experimental results, it was shown that all THMs concentrations were decreased after PAC contact, the decrease being higher for higher PAC dose and higher contact time, with few exceptions. This fact probably indicates that adsorption rate plus volatilisation rate of THMs overcame formation rate, in most cases.

It was also concluded that volatilisation and possible formation reactions of THMs had probably a more apparent effect to the total removal of most THMs at low PAC doses and low contact time. At higher PAC doses and higher contact time, PAC adsorption probably had an increased contribution to THMs removal, because of the larger carbon surface area and the longer contact time, resulting in higher adsorbed mass according to adsorption theory.

By using isotherm results of individual THMs on activated carbon by other researchers, the theoretically adsorbed mass of THMs per $\mathrm{g}$ of PAC was roughly estimated and compared with the measured removed mass of THMs per $\mathrm{g}$ of PAC at PAC dose $50 \mathrm{mg} \mathrm{L}^{-1}$ and contact time 60 min for most THMs, on the assumption of equilibrium achievement.

The removed mass of THMs by PAC appeared much higher than the theoretically adsorbed, especially for the most volatile members. The difference was attributed to volatilisation taking place in the open mixing tanks.

In conclusion, the practical results from the application of PAC for the removal of THMs are much better than expected from single adsorption by PAC. Volatility of THMs, especially of chloroform, substitutes for weak adsorbability and gives increased removal.

The influent DOC was almost constant in all experiments. The removal of DOC was generally higher for increased PAC dose and contact time. The mass removal of DOC per $g$ of PAC was higher by more than two orders of size than that of the smaller and in lower concentration THMs, as was expected.

\section{ACKNOWLEDGEMENTS}

The authors gratefully acknowledge the Athens Water Supply and Sewerage Company (EYDAP) for supporting this work.

\section{REFERENCES}

1. American Water Works Association (1990), Water Quality and Treatment, A Handbook of Community Water Supplies, $4^{\text {th }}$ edition, Mc Graw Hill, U.S.A.

2. APHA (1992), Standard Methods For the Examination of Water and Wastewater, $18^{\text {th }}$ ed., American Public Health Association, Washington.

3. Arora, H., LeChevalier, M.W., and Dixon, K.L. (1997), DBP occurence survey, AWWA, 89(6), 60 -68.

4. Babi K.G., Koumenides K.M., Makri C.A., Nikolaou A.D. and Lekkas T.D. (2009), Adsorption capacity of GAC filter-adsorber and postfilter-adsorber for individual THMs from drinking water, Athens, Proceedings of the $11^{\text {th }}$ International Conference on Environmental Science and Technology (CEST 2009), September 3-5, Chania, Krete, Greece.

5. Babi K.G., Koumenides K.M., Nikolaou A.D., Makri C.A. and Lekkas T.D. (2008), Pilot study of the removal of toxic THMs and HAAs from drinking water by GAC postfilter-adsorber in Galatsi WTP, Athens, Proceedings of the international conference "Industrial and Hazardous Waste ManagementChania 2008", October 1-3, Krete, Greece.

6. Babi K.G., Koumenides K.M., Nikolaou A.D., Makri C.A. Tzoumerkas F.K. and Lekkas T.D. (2007), Pilot study of the removal of THMs, HAAs and DOC from drinking water by GAC adsorption, Desalination, 210, 215-224. 
7. Babi K.G., Koumenides K.M., Nikolaou A.D., Mihopoulos N.S., Tzoumerkas F.K., Makri C.A. and Lekkas T.D. (2003), Pilot-plant experiments for the removal of THMs, HAAs and DOC from drinking water by GAC adsorption- Galatsi Water Treatment Plant, Athens, Global Nest:The Int. J., 5(3), 177184.

8. Chowdhury S. and Champagne P. (2008), An investigation on parameters for modeling THMs formation, Global NEST J., 10(1), 80-91.

9. Clark R.M. and Lykins B.W. Jr. (1991), Granular Activated Carbon, Design, Operation and Cost, 2nd ed., Lewis Publishers, Michigan, U.S.A.

10. Dvorak B.I., Lawler D.F., Speitel G.E., Darrell L.J. and Broadway D.A. (1993), Selecting among physical/chemical processes for removing synthetic organics from water, J. Water Environment Research, 65(7), 827-838.

11. EEC(1998) Council Directive 98/83/EC of 3 November 1998 on the quality of water intended for human consumption, Official Journal of the European Communities, L 330/32, 5.12.98.

12. Golfinopoulos S.K. and Nikolaou A.D. (2005), Formation of DBPs in the drinking water of Athens, Greece: a ten year study, Global NEST J., 7(1), 106-118.

13. LekkasT.D., Babi K.G., Koumenides K.M., Makri C.A., Lekkas D.F. and Nikolaou A.D. (2008), Removal of specific DBPs by GAC in Galatsi WTP, Athens, Proceedings of the conference 'Protection and Restoration of the Environment IX', July 1-4, 2008, Kefalonia, Greece.

14. Najm I.N., Snoeyink V.L., Suidan M.T., Lee C.H. and Richard Y. (1990), Adsorption on Powdered Activated Carbon: Effect of Particle Size and Background Organics, J. AWWA, 82(1), 65-76.

15. Najm I.N., Snoeyink V.L., Lykins Jr. B.W. and Adams J.Q. (1991), Using Powdered Activated Carbon: A Critical Review, J. AWWA, 83(1), 65-76.

16. Nieuwenhuijsen M.J. (2005), Adverse reproductive health effects of exposure to chlorination disinfection by products, Global NEST J., 7(1), 128-144.

17. Nikolaou A.D., Golfinopoulos S.K., Lekkas T.D. and Kostopoulou M.N. (2004), DBP levels in chlorinated drinking water: effect of humic substances, J. Environmental Monitoring and Assessment, 93, 301-319.

18. Nikolaou A.D., Lekkas T.D., Golfinopoulos S.A. and Kostopoulou M.N. (2002a), Application of different analytical methods for determination of volatile chlorination by-products in drinking water, Talanta, 56(4), 717-726.

19. Randtke S.J. and Snoeyink V.L. (1983), Evaluating GAC adsorptive capacity, J. AWWA, 75(8), 406413.

20. Sandrucci P., Merlo G., Genon G. and Meucci L. (1995), PAC activity vs by-product precursors in water disinfection, Water Research, 29(10), 2299-2308.

21. Singer P.C. (1994), Control of disinfection by-products in drinking water, Journal of Environmental Engineering, 120(4), 727-744.

22. Speth T.F. and Miltner R.J. (1990), Technical note: Adsorption capacity of GAC for synthetic organics, J. AWWA, 82(2), 72-75

23. Thacker W.E., Snoeyink V.L. and Crittenden J.C. (1983), Desorption of compounds during operation of GAC adsorption systems, J. AWWA, 75(3), 144-149.

24. Treybal R.E. (1980), Mass-Transfer Operations, McGraw-Hill Book Company, $3^{\text {rd }}$ ed., New York.

25. USEPA (1998), National Primary Drinking Water Regulations: Disinfectants and Disinfection ByProducts Notice of Data Availability, Office of Ground Water and Drinking Water, http:/www.epa.gov/OGWDW/mdbp/dis.html.

26. USEPA (1998a), EPA Method 551.1, USEPA, National Exposure Research Laboratory, Office of Research and Development, Cincinnati, $\mathrm{OH} 45268$.

27. USEPA (2001), Controlling Disinflection By-Products and Microbial Contaminants in Drinking Water, Office of Research and Development, Washington DC 20460, EPA/600/R-01/110, December 2001.

28. WHO (2004), Guidelines for drinking water quality, Vol. 1. Recommendations, $3^{\text {rd }}$ ed. 